\title{
Characterizing bird migration phenology using data from standardized monitoring at bird observatories
}

\author{
Endre Knudsen ${ }^{1, *}$, Andreas Lindén ${ }^{2}$, Torbjørn Ergon ${ }^{1}$, Niclas Jonzén ${ }^{3}$, \\ Jon Olav Vik ${ }^{1}$, Jonas Knape ${ }^{3}$, Jan Erik Røer ${ }^{4}$, Nils Chr. Stenseth ${ }^{1}$ \\ ${ }^{1}$ Centre for Ecological and Evolutionary Synthesis (CEES), Department of Biology, University of Oslo, PO Box 1066 Blindern, \\ 0316 Oslo, Norway \\ ${ }^{2}$ Department of Biological and Environmental Sciences, Integrative Ecology Unit, PO Box 65 (Viikinkaari 1), \\ Helsinki University 00014, Finland \\ ${ }^{3}$ Department of Theoretical Ecology, Ecology Building, Lund University, 22362 Lund, Sweden \\ ${ }^{4}$ Lista Bird Observatory, 4563 Borhaug, Norway
}

\begin{abstract}
Long-term data from standardized monitoring programmes at bird observatories are becoming increasingly available. These data are frequently used for detecting changes in the timing of bird migration that may relate to recent climate change. We present an overview of problematic issues in the analysis of these data, and review approaches to and methods for characterizing bird migration phenology and its change over time. Methods are illustrated and briefly compared using autumn data on garden warbler Sylvia borin from a standardized mist-netting programme at Lista bird observatory, southern Norway. Bird migration phenology is usually characterized rather coarsely using a small number of sample statistics such as mean, median and selected quantiles. We present 2 alternative approaches. Smoothing methods describe the within-season pattern in the data at an arbitrary level of detail, while fitting a parametric seasonal distribution curve offers a coarse description of migration phenology relatively robust to sampling effects. Various methods for analyzing linear trends in the timing of bird migration are reviewed and discussed. Exploratory studies using longterm data gathered at bird observatories can yield more detailed insight into the phenomenon of bird migration and how phenologies relate to climate. Methodological advances are needed, particularly in order to better characterize the shape of phenological distributions and separate between sampling effects and 'true' phenology.
\end{abstract}

KEY WORDS: Bird migration phenology - Climate change - Bird observatories · Monitoring · Day-to-day variability $\cdot$ Seasonal model $\cdot$ Smoothing

- Resale or republication not permitted without written consent of the publisher

\section{INTRODUCTION}

Phenology is commonly defined as the study of the timing of periodically recurring biological phenomena (see Walther et al. 2002). Bird migration is a prime example, the phenology of which has been studied for $>250$ yr (Lehikoinen et al. 2004), with more than a century of investigation of the causes underlying its variability within and between years (reviewed by Lack 1960). Many studies have linked changes in the timing of migration with large-scale climate factors and interannual variability in weather (reviewed by Lehikoinen et al. 2004). Yet, our understanding of responses to climate change remains quite limited.

Long-term, standardized monitoring data from bird observatories at 'hotspots' along the migratory route are becoming increasingly available. These data are unarguably the best available on the migration of many species, in terms of their resolution (daily data) and constancy of sampling effort between years and 
within a season (standardized trapping or observation protocols), and allow analysis of the whole seasonal distribution of migration (Lehikoinen et al. 2004, Sparks et al. 2005). Seasonal totals from monitoring are also used for modelling population dynamics and change (Francis \& Hussel 1998, Knape et al. in press). All survey efforts will, however, have their shortcomings (Bibby 2000), and there are several problematic issues specific to these data.

Understanding the timing of biological events is a classical problem in life-history evolution (Lack 1968, Iwasa \& Levin 1995). The timing of spring migration sets the limit for the onset of breeding, and thus affects the match between food requirements and availability (Visser et al. 2004). Optimal adjustment of the timing of migration and breeding in birds due to recent climate change depends on factors such as mortality during migration (Sillett \& Holmes 2002, Newton 2006), prebreeding mortality and competition for territories (Jonzén et al. 2007), and phenological changes in food or predators (Stenseth et al. 2002, Visser \& Both 2005, van Asch \& Visser 2007). Estimating parameters such as mean arrival time only captures certain features of the phenology. To better understand population consequences of changes in the temporal match between phenologies, we need models describing how migration intensity varies through the season.

However, it is not obvious how to model the phenology of bird migration. Weather conditions en route affect the large-scale migratory movements of birds; that is, the observed daily numbers of migrating birds fluctuates (at time scales longer than a day, but shorter than weeks), making bird migration past any particular location appear wavy through the season (Cooke 1913). The conceptually simple model of a unimodal, bell-shaped curve may often provide an adequate measure of the central tendency for migration dates. However, it cannot account for the above-mentioned weather effects or for mixtures of several populations, sexes and age groups, which are frequently evident from the data.

Bird migration phenology has traditionally been described using simple measures of central tendency (mean, median or mode) and spread (first and last observations, or low and high quantiles, e.g., 5 and $95 \%$ quantiles). Changes in the timing of migration and its relationship with covariates such as the North Atlantic Oscillation (NAO) index have usually been inferred on the basis of correlation analysis, simple linear regression, or analysis of variance (ANOVA), though sometimes using partial correlation, multiple linear regression, or generalized linear models (GLM). Regression coefficients for different species have then been treated as independent and either discussed independently, as samples from some predefined bio- logically relevant groupings such as long-distance and short-distance migrants, or (less frequently) subjected to a multivariate analysis (Tryjanowski et al. 2002, Hüppop \& Hüppop 2003), in search of patterns.

To model phenology and changes in phenology more accurately and in more detail, one must deal with various sampling problems, such as incomplete observations, observation error, and varying sampling effort, to get closer to specific features of the 'true' underlying seasonal distribution or changes in phenology. This may involve smoothing away day-to-day variability, fitting a seasonal distribution curve, or incorporating random effects in the model to account for statistical dependence between observations.

In this paper, we review different approaches to describing bird migration phenology and detecting its change. Our emphasis will be on the former, since relevant and accurate parameter estimates are a prerequisite for detecting change. Table 1 presents an overview of the case studies reviewed. We have limited ourselves to studies using data from standardized monitoring efforts, as these are the most frequently used and are designed to control for some error sources. However, many problematic issues are common to both standardized and less standardized monitoring data. We illustrate and briefly compare methods using data on a long-distance migrant from a Norwegian bird observatory. Some future challenges in the modelling of bird migration phenology and its change will be identified. However, we start by looking more closely at the nature of data from bird observatories and reviewing the challenges researchers meet in their analysis.

\section{THE SIGNAL OF BIRD MIGRATION}

Fig. 1a is an illustrative example of the raw data obtained from standardized monitoring programmes at bird observatories: the daily number of mist-netted garden warblers Sylvia borin at Lista bird observatory $\left(58^{\circ} 6^{\prime} \mathrm{N}, 6^{\circ} 34^{\prime} \mathrm{E}_{\text {; }}\right.$ near the southernmost tip of Norway) autumn 2004. Such data may need to be cleaned to some extent; for the present example, only first-year birds not previously captured in the same season were included in further analyses $(\mathrm{n}=106 ; 2$ adult birds were netted on 20 July and are marked in the plot with a dashed vertical bar). Ideally, this time series would be an unbiased estimate of the migration phenology for this location and year. However, what we actually have is an incomplete series of observations of a stochastic signal (bird migration) contaminated by observation error (location-specific effects and sampling effects, including bias and varying effort). The within- and between-seasonal varying expectation of this signal is 


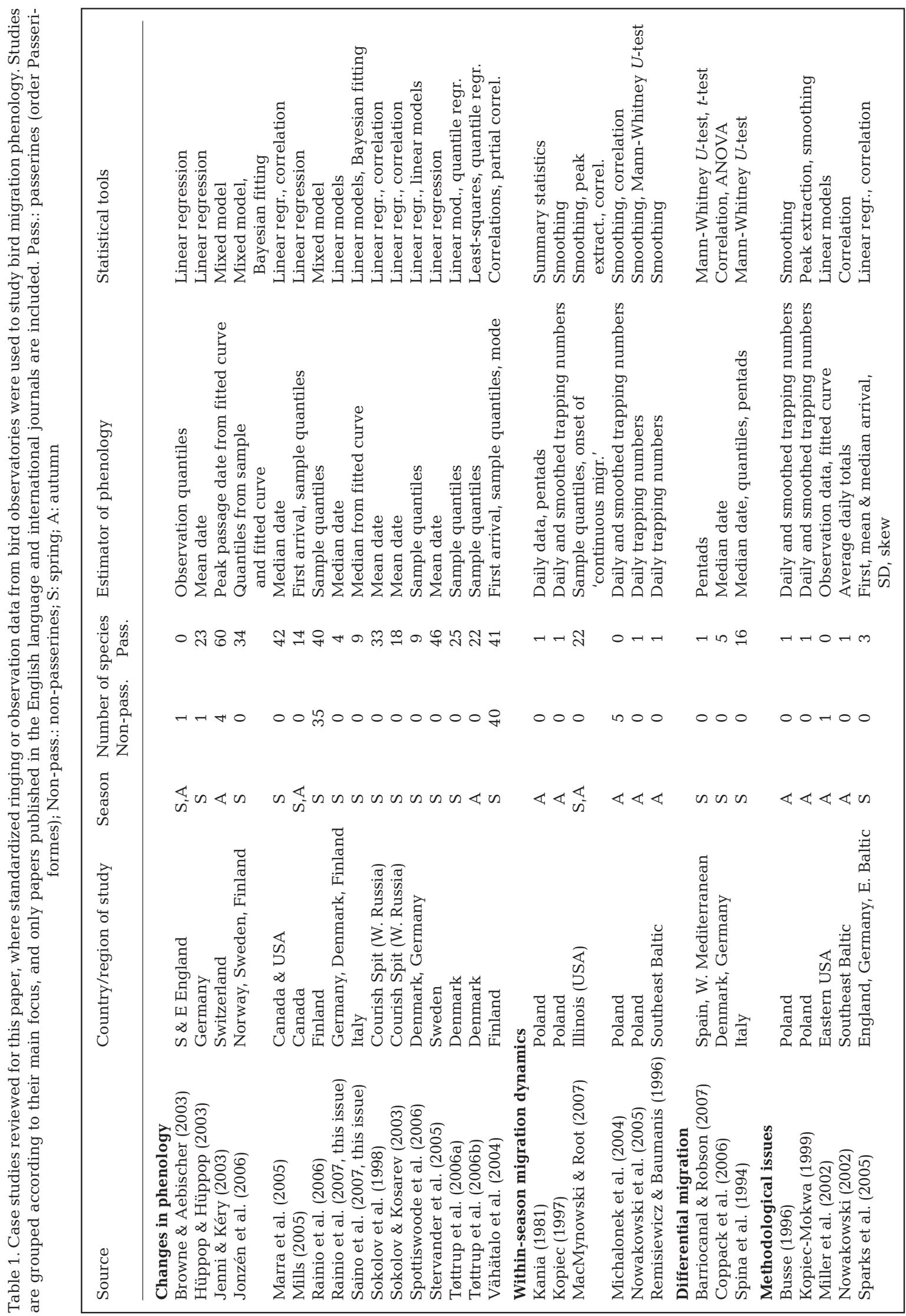




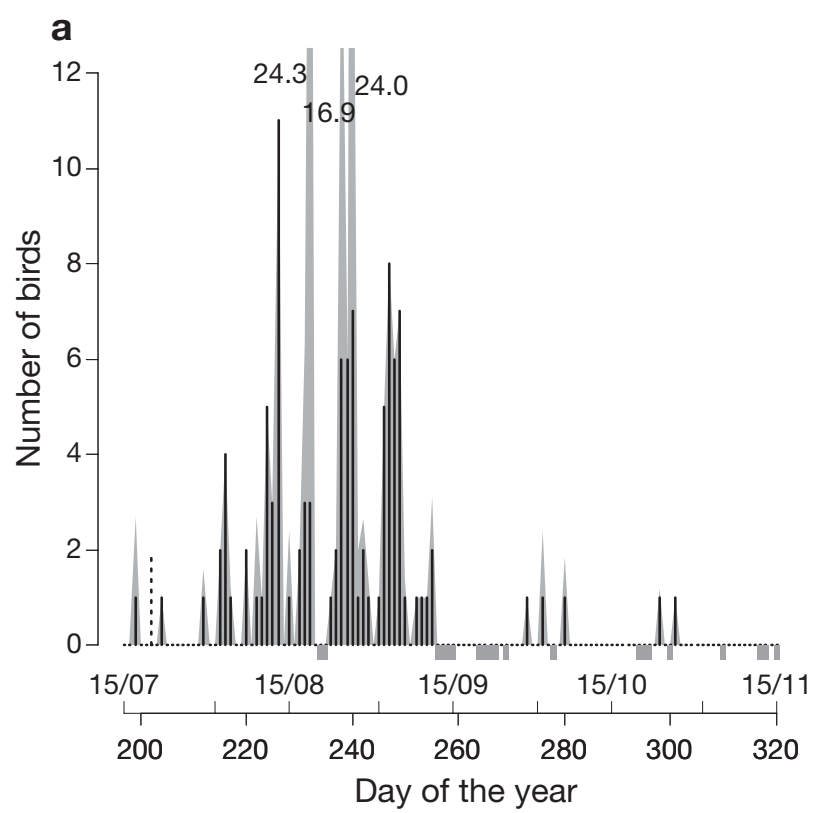

b

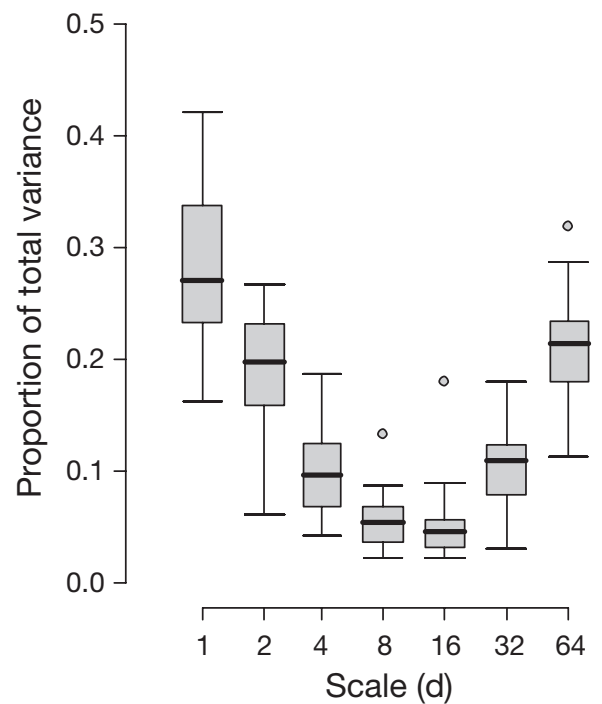

Fig. 1. Sylvia borin. Bird migration phenology as observed from standardized monitoring programmes at bird observatories. (a) The daily number of mist-netted, first-year (solid bars) and adult (dashed bar near the left edge) garden warblers at Lista bird observatory autumn 2004. Days without mist netting are indicated by grey boxes below the bars, and the grey shaded area behind the bars indicates the expected number of birds under constant and full trapping effort. (b) Partitioning of the yearly signal's variance across observation scales, calculated from a wavelet transform. The box plot summarizes the between-year variability from 1990 to 2004. Shaded boxes delimit the interquartile length, horizontal bars represent the median, whiskers extend to data points no more than 1.5 times the interquartile range, and open circles denote outliers

what we usually want to estimate and characterize as migration phenology, but the unknown observation error complicates matters (see also Lehikoinen 1993). Some of the problems typically encountered, regardless of the degree of standardization, are discussed in sections 2.1 to 2.6 that follow:

\subsection{Missing days}

Even though this bird observatory was permanently manned throughout the monitoring periods, there were $20 \mathrm{~d}$ when weather did not permit mist netting. We cannot safely assume that these days are missing at random. In our example, several periods of up to 4 contiguous days are missing, particularly in the middle to late part of the season, as expected from the generally unstable and deteriorating weather conditions at this time of the year. Some techniques for data analysis require daily observations, and interpolation may introduce bias. In this case, weather observations revealed that all missing days were windy (>11 $\left.\mathrm{m} \mathrm{s}^{-1}\right)$ and/or rainy, conditions under which there is usually very little observable passerine migration. A pragmatic approach would be therefore simply to assume that no birds would be captured in the mist nets (i.e. substitute missing values with zeros). Alternatives to this simple method would be to impute data for the missing days using regression with non-missing data or the expectation-maximization (EM) algorithm (Dempster et al. 1977, Morgan 2000). However, these techniques assume that data are missing at random. Multiple imputation (see Schafer 1999) based on a probabilistic model taking into account the weather situation on the present day and the migration intensity on neighbouring days would be somewhat simpler and directly incorporate a stochastic component.

\subsection{Non-constant daily effort}

In monitoring schemes, the protocol is typically highly standardized regarding the numbers of nets in use, their position and the operating hours. Nevertheless, mist nets will have to be closed in heavy rain and/or strong wind for animal welfare reasons. Under such conditions, very few birds would be trapped even if the nets were left open. At other times, the influx of birds in the mist nets may be too large for the personnel to handle birds quickly enough to permit keeping all mist nets open. If there is a record of the operating hours of the mist nets, some sort of correction for nonconstant effort can be applied (e.g. by standardizing the daily catches to the daily number of mist net hours, 
as illustrated in Fig. 1a). However, bad weather may affect both trapping effort and 'true' migration intensity. Also, the seasonal change in day length may need to be taken into account, the exact timing of trapping efforts may matter since migration intensity varies through the day, and mist nets may catch different species to different extents according to their exact location relative to habitat preferences. Making good corrections for varying effort is not trivial, and it may suffice to include a simple index of trapping effort as an offset (a covariate with the coefficient fixed to 1) in the model. Another option would be to weight observations by trapping effort, but the consequences of this for estimating phenology are unclear, and the choice of weighting schemes is non-trivial and affects the results.

\subsection{Truncation}

Failing to include the beginning or end of migration in the trapping period will introduce a bias in estimates of migration timing as well as total numbers of migrants observed over the season. The data in Fig. 1a do not seem to be truncated, though it is hard to say what the situation would be if we were also considering adult birds, since only 2 adults were trapped near the start of the season. Whether truncation is a problem or not varies between species and between years. In some cases, though rarely for passerines in seasonal environments, migration periods may be rather indistinct or even blend together, making their delimitation somewhat arbitrary if biological cues, such as age or moult, are not available. Climate change may increase the risk or severity of truncation due to a shift in the timing of migration and longer or thicker tails in the distribution of arrivals (e.g. more migrants early in spring and late in autumn). Few good remedies for truncation are available, but peaks in migration intensity may be identified even if the tails are truncated, and it may still be possible to fit curves to the part of the distribution that is observed. Bayesian estimation may be helpful in constraining parameter estimates to sensible values and accommodating the extra complexities (see e.g. Jonzén et al. 2006, Saino et al. 2007, this issue).

\subsection{Autocorrelation}

Bird migration is a flux affected by spatially and temporally correlated variables such as weather. Hence, the number of birds observed on consecutive days is usually correlated. Autocorrelation implies a dependency between neighbouring observations, and has traditionally been regarded as a nuisance to ignore or get rid of, but it can also be modelled explicitly using time-series methods. Numeric maximum-likelihood estimation allows dependencies between errors to be modelled and estimated. We recommend spending some time studying within-year autocorrelation in bird migration signals for its own sake, as it indicates the impact of weather and other factors structuring the migration flux. However, it is not simple to separate between the various causes for autocorrelation, and observed autocorrelation may partly be due to failure in adequately removing a seasonal trend. Also, autocorrelation indices calculated over the entire season tend to be hard to interpret in the current setting, where the absolute positions of elements in the time series matters. 'Moving window' alternatives, such as the local Moran's I (Anselin 1995), estimate the autocorrelation only in a small neighbourhood around the focal point, and can thus pick up patterns which might otherwise be missed.

\subsection{Non-stationarity}

Statistical inference frequently assumes stationarity, i.e. that the probability distribution of variables or error terms remains constant over time. However, mean migration intensity clearly changes throughout the season. Subtracting a seasonal trend, or differencing daily data, may leave a signal that is closer to stationary. The variance, too, is likely to change over the season. In general, variance increases with increasing mean, and this is also expected in bird migration data, where 'zero-days' typically will be interspersed with good migration days throughout the season. On the other hand, variability between years is, at high latitudes, expected to be larger early in spring or late in autumn, when variability in weather and the sensitivity of migration to such is largest (Sokolov et al. 1998, Vähätalo et al. 2004). Overdispersed Poisson models (where extra-Poisson variability in the error term is modelled) may accommodate both the mean-variance relationship and other variance components (see e.g. Jonzén et al. 2006).

\subsection{Biological interpretation}

The interpretation of the observed migration intensity may change throughout the season, as we may not be sampling the same population throughout. In spring, high-latitude populations may be expected to migrate later than those from lower latitudes, and it is quite common for males to migrate earlier than females (protandry; reviewed by Morbey \& Ydenberg 2001). In autumn, we have a mixture of adult and first-year 
birds, and these may or may not migrate in different parts of the season. In the early part of the season, we may, to a varying extent, be picking up small-scale pre-migratory movements rather than true migration. Since the timing of migration of individuals within a population depends on factors specific to the individuals, such as migratory distance (Hötker 2002) and build-up of fuel loads (Marra et al. 1998), and fuel deposition rate varies within the season (Schaub \& Jenni 2000), we are likely to sample different population segments in different parts of the season. Mass movements, such as those observed for invasive species or following cold spells late in autumn, would obviously be an exception.

While we have indicated alleviating measures to some of the above problems, some components of observation error may never be handled properly. For instance, a time-varying bias is introduced simply because the positions of mist nets (or other trapping equipment) are fixed, while their capture success and birds' relative use of different habitats vary with weather conditions.

Different levels of variability in the data can be distinguished in Fig. 1a: from day-to-day variability, through waves of a week's length or more, to a largescale unimodal or perhaps bimodal pattern. The variability at the smaller scales is a combination of sampling variability and actual variability in the intensity of migration, while at the larger scales it closely reflects the overall shape of the phenological distribution. Even if we cannot separate 'true phenology' from observation error, it is useful to ask ourselves how the variability in the data is distributed across observation scales, since this indicates the relative contribution of processes at different scales. Also, if data from different years mainly differ in their small-scale variability, differences in the overall timing of migration are not important in determining the overall shape of the phenological distribution. Fig. $1 \mathrm{~b}$ is based on a decomposition of the total variance of the daily data on garden warblers at Lista into components of different observation scales, using wavelet coefficients from a maximum overlap wavelet transform using the 'least asymmetric' wavelet of nominal width 8 (LA8). The component at scale $j$ describes variability in a weighted average of observations on $j$ consecutive days (e.g. day-to-day variability is at a scale of $1 \mathrm{~d}$ ), and weights are defined in a manner that does not introduce dependence across scales. The box plot shows the variability between years of these empirical power spectra for the period from 1990 to 2004. We see that the largest proportion of variance is typically found at the smaller scales (indicating sampling and weather effects), while variability between years is comparable at small and large scales.
If we scale the bird migration signal by dividing with the total number of birds observed during the season, we obtain the (biased) empirical frequency distribution of ringing or observation dates. Alternatively, cumulative distributions can be used directly for certain nonparametric distributional tests, such as the Kolmogorov-Smirnov test. For instance, Jounela et al. (2006) modelled the cumulative run of Atlantic salmon Salmo salar with a logistic function. However, consecutive values of the empirical cumulative distribution function are not independent: a sudden rush of migrants will heavily influence the shape of the curve for all succeeding time values. Truncation or missing days are also more problematic for cumulative distributions. Hence, we prefer in the following to work with daily numbers rather than cumulative.

\section{MODELLING BIRD MIGRATION PHENOLOGY}

\subsection{Covariates}

In the present paper, we are content with simply modelling the temporal pattern of bird migration (time within season as the only covariate) and not the effect of other covariates per se. However, one could, for instance, be interested in the effect of weather covariates on migration, or in controlling for such when estimating population size. For mechanistic modelling of daily trapping numbers, it appears promising that the migratory movements of individual birds can, in part, be explained by simple behavioural rules to reduce time or energy expenditure during migration and stopover (see Hedenström \& Alerstam 1997, Weber \& Houston 1997, Schaub et al. 2004, Liechti 2006). However, even if the inclusion of covariates is straightforward, the interpretation is not necessarily so. (1) Winds, temperature and rainfall are not the whole story; in fact, a large number of candidate variables interact (Table 2; see also Gordo 2007, this issue), and it is hard to know a priori which variables to include and what shape to assume for the response function. (2) Species and individuals respond differently, and the shape of the response function may be conditional on sex, age, internal state, season and external covariates. (3) Dayto-day variability is not only affected by small-scale processes and the general seasonal pattern of occurrence, but also by a number of intermediate-scale processes of partly stochastic nature (such as the movement of weather systems) or that are hard to quantify, such as social interactions, intensity of competition and predation pressure (Moore \& Yong 1991, Helm et al. 2006, Trnka \& Prokop 2006). (4) Bird migration is a flux of organisms, and the weather situation at the study site is not necessarily a good predictor for the number 
Table 2. Some variables likely to affect the probability of observing/ trapping a bird at a given day and location en route during migration. Variables are classified according to the typical time scale of influence and whether primarily exogenous (environmental), endogenous (due to 'internal' factors specific to the individual), or a result of interactions between the 2 . Variables mainly related to the observation process are not included

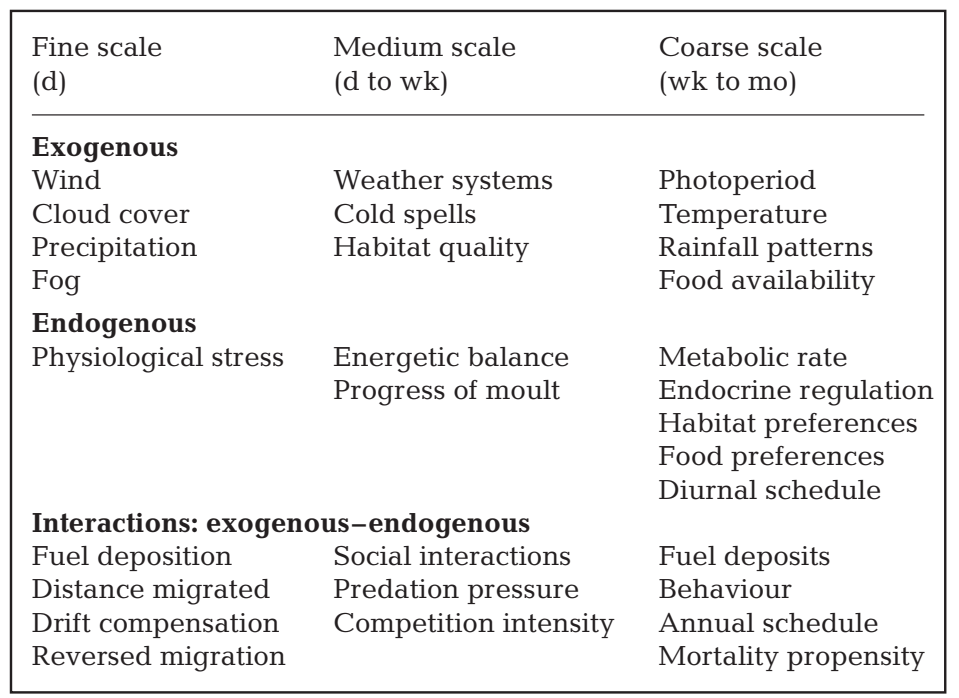

of birds occurring there. (5) For many species, the birds captured or observed are on stopover, so the capture rate on a particular day is a function of both previous influx and current efflux, which is typically differently (sometimes oppositely) affected by covariates.

Even if our interest is solely in modelling the intensity of bird migration through the season, it could be sensible to include covariates other than time in the model. For instance, by including weather covariates accounting for day-to-day variability in capture probability (observation error), one may identify the remaining pattern more clearly. On the other hand, the same weather covariates may also affect 'true' migration intensity, which we would not want to control for, so the desired effect can be hard to obtain in practice. It could be argued that local weather conditions (such as mist) will mostly affect capture probability, whereas large-scale weather patterns (such as air-pressure fields and temperatures on the previous day in the source areas of migrating birds) would mainly affect migration activity. However, small-scale and large-scale weather conditions are often strongly correlated.

As a first step, progress could be made by looking more closely at the way variables interact and the possibilities for reducing the dimensionality of variables and aggregating variables into relevant 'packages'. For instance, other species of migrants, large-scale climate indices, or composite variables such as principal components may be included as proxy variables, i.e. covariates that may not be mechanistically important, but that can 'soak up' effects of covariates not included, to avoid these from becoming part of the error term. Further work is also needed on determining the appropriate time windows and spatial extents for the impact of variables such as temperature, rainfall and the NAO index (see Ahola et al. 2004 and Hüppop \& Winkel 2006).

Alternatively, if our interest is mainly in controlling for unknown sources of variability in the data, these may be accounted for by random effects (e.g. random day effects in common with a set of species that will 'soak up' effects of weather). If important covariates are unobservable or the observation process is complex, more explicit forms of latent-variable modelling may be required (de Valpine \& Hastings 2002).

\subsection{Smoothing}

Smoothing can be defined as the use of (mainly nonparametric) tools to capture patterns in observed data, yielding a less variable signal where noise is reduced and no rigid form of the relationship between predictor and response variables is assumed. We will only con-

Table 3. Expectation and variance of skewness estimates [E(skew) and Var(skew), respectively] from 10000 simulations of a symmetric, a positively skewed and a negatively skewed seasonal distribution of length $93 \mathrm{~d}$ (the spring observation period for our sample data). For each simulation run, 100 birds were randomly and independently assigned to day numbers according to a beta distribution. Skewness was calculated on the basis of raw data (top row), as well as smooths (from kernel density estimates using a Gaussian kernel of the specified width)

\begin{tabular}{|c|c|c|c|c|c|c|}
\hline \multirow[t]{2}{*}{ Kernel width (SD) } & \multicolumn{2}{|c|}{$\begin{array}{c}\text { Symmetric } \\
(\text { mean }=46.5, \text { skew }=0)\end{array}$} & \multicolumn{2}{|c|}{$\begin{array}{c}\text { Positive skew } \\
(\text { mean }=26.6, \text { skew }=0.597)\end{array}$} & \multicolumn{2}{|c|}{$\begin{array}{c}\text { Negative skew } \\
(\text { mean }=66.4, \text { skew }=-0.597)\end{array}$} \\
\hline & E(skew) & Var(skew) & $\mathrm{E}($ skew $)$ & Var(skew) & $\mathrm{E}($ skew $)$ & Var(skew) \\
\hline - & 0.001 & 0.030 & 0.579 & 0.037 & -0.576 & 0.036 \\
\hline 1 & 0.001 & 0.030 & 0.573 & 0.036 & -0.575 & 0.036 \\
\hline 5 & 0.0007 & 0.020 & 0.556 & 0.027 & -0.558 & 0.027 \\
\hline 10 & -0.001 & 0.006 & 0.548 & 0.013 & -0.547 & 0.013 \\
\hline
\end{tabular}


sider the case of 1 response variable $y$ (bird abundance or some index for this) and 1 predictor variable $x$ (day number), also called scatterplot smoothing. The challenge is to find a smooth approximation of bird migration phenology based on observations of $x$ and $y$. This has rarely been done, but there are at least 3 immediate motives for doing it: (1) to focus on time scales longer than those of the raw observations, either because they are biologically more relevant or simply to reduce noise, (2) to allow for missing days or sparse data, and (3) to allow for the flexible description of phenology suggested by the data. The latter is especially useful for studying between-year variability in the data, particularly if the phenological distribution is complex in shape or varies between years. As shown in Table 3 for simulated data, smoothing can decrease the 'pure chance' variability in parameter estimates (here, of skewness), while the bias only slightly increases with increasing smoothness. Hence, the parameterization of phenology from smoothed data appears attractive. Smoothing does, however, assume data of adequate quality; apart from changing the resolution, it does not deal with problematic issues regarding sampling and representativeness of the data. Although several smoothers allow missing data, they are, to a varying degree, sensitive to it.

\subsubsection{Smoothing techniques}

In Fig. 2, various techniques of smoothing were applied to the example data previously presented. The techniques are briefly presented below; we refer to the supplementary online appendix (available at www.intres.com/articles/suppl/c035p059_app.pdf) for a more thorough treatment. All data analyses for the present paper, as well as the preparation of figures, were performed in ' $R$ ' v. 2-4-1 ( $R$ Development Core Team 2006), with the aid of the add-on packages 'chron' (James \& Hornik 2007), 'Kendall' (McLeod 2005), 'MASS' (Venables \& Ripley 2002), 'quantreg' (Koenker 2006), 'sfsmisc' (Maechler 2007), 'sn' (Azzalini 2006) and 'waveslim' (Whitcher 2006).

(1) The moving average smooths in Fig. 2a were obtained by calculating the average over a window of fixed width that moves across the data, visiting the elements of the time series successively. Missing data can be omitted from calculation or imputed. Increasing window size increases the smoothness (though the curve will always appear somewhat jagged), but also increases bias, which in fact is a general pattern for all smoothing techniques discussed here.

(2) LOESS smoothers make use of local regression within a moving window, where $k$ nearest neighbours around the point of interest are weighted in a manner putting most weight on the closest neighbours. The degree of smoothing is usually determined by supplying the span of the window, in Fig. 2 b reported as the fraction of the total length of the time series. The curves are clearly much smoother than those of the simple moving average. Fitting a second-order polynomial rather than a straight line increases the ability to pick up local features.

(3) A kernel smoother may be written on the form $\hat{f}(x)=(n h)^{-1} \sum_{i=1}^{n} K\left[\left(x-x_{i}\right) / h\right]$, where $K(x)$ is a kernel function integrating to 1 and $h$ is the width of the smoothing window, also known as the smoothing parameter or bandwidth (Silverman 1986). In other words, the kernel smoother fits a constant at each element of the time series by applying a weighted average over a local neighbourhood, similar to a weighted moving average. Popular choices for the kernel are the rectangular (uniform), triangular, Gaussian, Epanechnikov, biweight and cosine functions. As illustrated in Fig. 2c, the choice of the kernel function does not affect our estimate much, but less smooth kernels such as the rectangular produce less smooth estimates due to discontinuities.

Ader (1993) and Busse (1996) performed kernel smoothing on bird migration data. They used different weighting functions, but both authors performed the smoothing iteratively until adequate smooths were obtained. Kernel functions will quickly approach the Gaussian kernel of increasing width when applied iteratively, so a better option may be to smooth noniteratively using appropriate smoothing parameters.

(4) The wavelet transform is a relatively new technique that has become an exciting alternative for analyzing time-series data (Percival \& Walden 2000). In effect the discrete wavelet transform is a kernel smoother with kernel functions (wavelets) designed to satisfy certain conditions that make the transform orthonormal. Such transforms are attractive since they transform the data into a mathematically equivalent representation (Fourier analysis being another example). From a practical perspective, the main attraction is a decomposition of the time series into a set of timescale components of the same length as the original series, each component describing the time development of the signal at a particular observation scale. The transform may be performed in ways that easily enable estimating the signal's power spectrum (i.e. the dispersion of variance across observation scales rather than time). A drawback is that missing data will have to be imputed. As seen in Fig. 2d, the smooths are visually very appealing while performing reasonably well. They do, however, occasionally dip slightly below zero, due to negative coefficients in the wavelet.

(5) A spline $\hat{g}(x)$ is a piecewise polynomial approximation of a smooth function (Hastie \& Tibshirani 1990, 

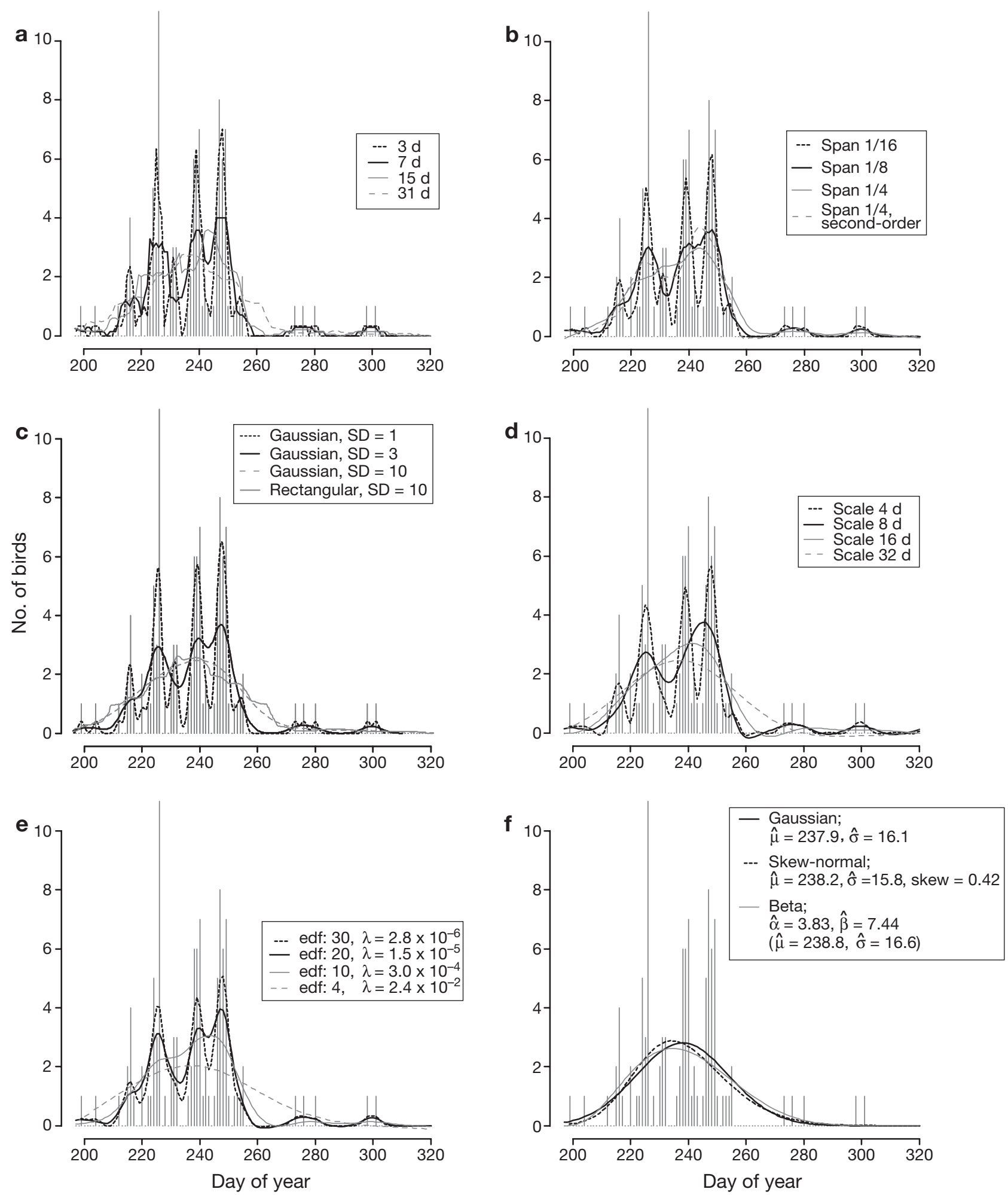

Fig. 2. Sylvia borin. Smoothing (a to e) and parametric fitting of seasonal distribution functions (f), applied to the data plotted in Fig. 1a (grey bars). (a) Moving average; (b) LOESS smoothing using first- and second-order polynomials and different smoothing spans; (c) kernel smoothing using different kernel functions (smoothing parameters are reported as the standard deviation of the kernel function); (d) wavelet smooths corresponding to the wavelet transform described in the text; (e) cubic smoothing splines with the number of knots equal to signal length (smoothing parameters are reported along with the equivalent degrees of freedom [edf] for the smooth); and (f) maximum-likelihood fit of the Gaussian (solid black), skewed normal (dashed black) and scaled beta (solid grey) seasonal distribution functions. For all fitting purposes, normally distributed errors were assumed, in order to facilitate comparisons 


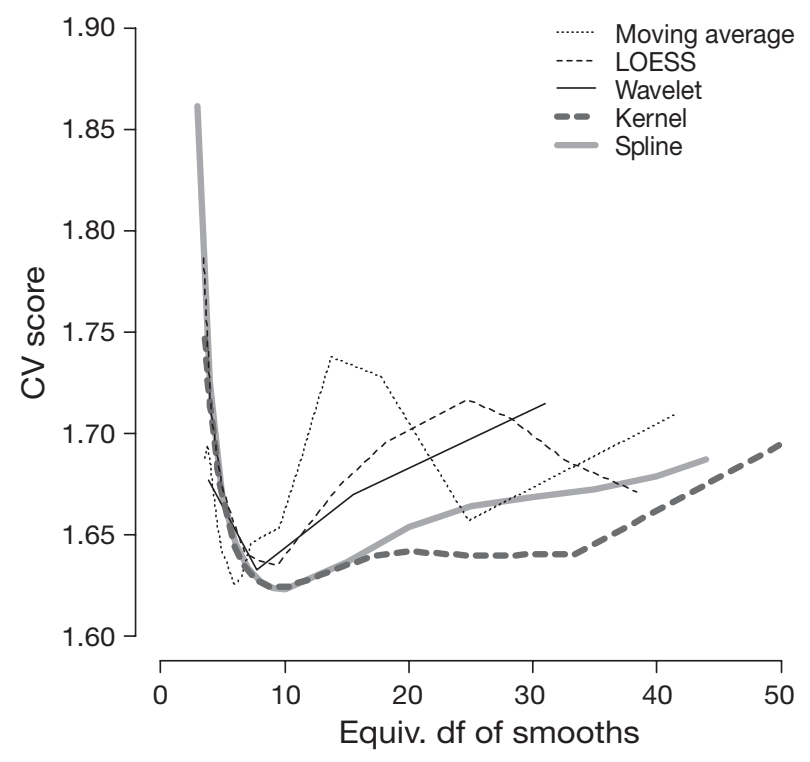

Fig. 3. Sylvia borin. Mean bias (1990 to 2004) for smoothers, using data previously presented. The degree of smoothing is represented by the equivalent degrees of freedom (edf) for smooths and bias as the ordinary cross-validation (CV) score for yearly smooths. A Gaussian kernel was used for kernel smooths; and a second-order polynomial, for LOESS smooths. For comparison, the mean CV score for the Gaussian fit of Fig. $2 \mathrm{f}$ is 4.39 , and the range of the CV score for the kernel smoother is from 0.42 to 4.84 at approximately 4 edf

Wood 2006). A smooth function is here understood as one that has derivatives of all finite orders, while a spline will typically consist of cubic polynomials joined together at so-called knots in a way that makes the entire spline continuous up to and including the second derivative. These cubic splines have several desirable attributes; in particular, they can in many cases be shown to be optimal or near-optimal interpolators. Fitting a cubic spline to data typically involves minimizing the expression $\sum_{i=1}^{n}\left[y_{i}-g\left(x_{i}\right)\right]^{2}+\lambda \int g^{\prime \prime}(x)^{2} \mathrm{~d} x_{\text {, where }}$ the smoothing parameter $\lambda$ determines the balance between producing a good fit and a smooth function. An appropriate choice of $\lambda$ can be determined by (generalized) cross-validation, and the model fitted using penalized least squares/penalized likelihood (Wood 2006) or the method of backfitting (Hastie \& Tibshirani 1990). This is, however, not always successful, frequently due to overfitting (in our case it suggested 43 degrees of freedom for the smooth; compare this with the smooths in Fig. 2e).

\subsubsection{Comparing and interpreting smooths}

As illustrated in Fig. 3 for our example data, there are no large differences between smoothers with respect to their bias, as gauged by cross-validation error (here we used ordinary cross-validation to enable comparison with non-linear curve fitting, and estimated equivalent degrees of freedom from the diagonal elements of the smoother matrix; see e.g. Hastie \& Tibshirani 1990). The amount of smoothing should be of more concern. This may also be determined on the basis of cross-validation (selecting the parameter corresponding to the minimum CV score; see Fig. 3), but optimization algorithms can get stuck at local minima, and, as previously illustrated for splines, minimizing the CV score does not guarantee that our smooth makes biological sense. We should have some a priori idea on how much we want to smooth and attempt to interpret the results in terms of biology. While smoothing certainly is a valuable tool for describing the intermediate-scale 'waviness' of observed bird migration or looking past the noise of daily data, the level of detail that can be picked up is limited by the data, and, as previously discussed, these are subject to sampling effects and observation error. Also, we must keep in mind that describing patterns does not imply mechanistic explanations (though it may be suggestive). For instance, if our interest is primarily in how the (latent) timing of migration has changed, multimodality due to different populations or population segments may be of interest, but it is rather a nuisance if caused by weather systems impeding migration.

\subsection{Fitting seasonal distribution curves}

An intuitively attractive way to model phenology is to describe the expected phenological distribution as some parametric function of time. The idea could be put into words by asking: 'when would the birds want to arrive?' or 'what would the perfectly observed distribution of arrival look like under constant ideal migration conditions?' This approach can be considered particularly useful when days are missing at random or truncation is present in the observation effort (Jonzén et al. 2006). The problem is managed statistically by considering the days of observation as samples of phenology at a given point in time. Summary statistics, such as mean, variance, skewness and different percentiles, can easily be calculated from the fitted distribution instead of calculating them from the raw data. Among the few examples of fitting distribution curves to phenological events, Miller et al. (2002), Jenni \& Kéry (2003) and Jonzén et al. (2006) fitted Gaussian curves to describe the timing of bird migration. Malo (2002) fitted unimodal curves based on modified sine functions to flowering phenology; Singh et al. (2006) quantified changes in rice growth patterns by fitting Gaussian curves to NDVI data; and Mäntyniemi \& 
Romakkaniemi (2002) used a Dirichlet distribution to model run timing of smolts in stocked Atlantic salmons, as part of a larger hierarchical Bayesian mark-recapture model. Peron et al. (2007, this issue) fitted 3 differently shaped unimodal distributions to daily indices of birds trapped during post-nuptial migration, and estimated peak migration dates from the model with the best least-squares fit.

\subsubsection{Different distributions - modelling expected phenology}

According to the theory of quantitative genetics, the frequency of a quantitative trait regulated by several genes will be approximately normally distributed as the number of genes or loci becomes sufficiently large (e.g. Roff 1997). There is a considerable amount of heritable genetic variation in the timing of migration, both in birds (Møller 2001, Pulido et al. 2001) and in some fish species (Quinn et al. 2000). Hence, there is theoretical justification for using a Gaussian function as a starting point for approximating the distribution of migration events if we assume that the timing of migration is a quantitative trait. Three parameters need to be fitted: mean, variance and maximum intensity. Some empirical studies suggest that phenology is fairly well approximated by a Gaussian function (Miller et al. 2002, Dahl et al. 2004, Jonzén et al. 2006).

If the distribution of phenology is clearly skewed, a skew-normal distribution (Azzalini 1985) can be used. The normal and skew-normal distributions are continuous and defined for all real numbers. Thus, they always gain positive values, leading to arbitrary delimitation of the beginning and end of the phenological distribution. A flexible alternative is to use a scaled beta distribution, which is defined on the interval $[0,1]$ using the shape parameters $\alpha$ and $\beta$ (for our purpose, length, location and maximum intensity will also have to be fitted). Alternatively, Malo (2002) proposed a flexible distribution with 5 parameters (start, duration, maximum intensity, skewness and length of the tails), which was successful in modelling unimodal flowering phenology of varying shape. In Fig. 2f, we have plotted the maximum-likelihood fit of the normal, skew-normal and scaled beta distributions. For comparison with the smooths, we assumed normally distributed errors, though, for instance, Poisson-distributed errors would be more sound (as discussed later).

Migration is not necessarily unimodal. One way to model multimodal phenology is to sum several parametric functions. The number of phenological distributions can be determined by model selection (e.g. using the Akaike information criterion), but it may be preferable to determine it on biological grounds.

\subsubsection{Error structure and model fitting}

Fitting seasonal distribution curves does not seem too popular, possibly due to the many ways of modelling the expectation and the error distribution, as well as the potential problems (e.g. with convergence in iterative, non-linear fitting procedures). In the simple case of a unimodal distribution behaving nicely, it is worth noting that the normal distribution reduces to a second-order polynomial on a logarithmic scale. Thus, assuming a Gaussian curve as the phenological distribution and a multiplicative log-normal error structure with independent observations, the curve can, on a log-scale, be fitted by a second-order polynomial regression.

Numeric maximum-likelihood methods and Bayesian methods add some flexibility to the models used. The typically huge day-to-day variation can then be modelled more closely. If a bird of a given species is thought to be observed independently of other birds the same day, the number of birds trapped on that day can be modelled with a Poisson distribution, where the day-specific expected value $(\lambda)$ is described by a seasonal distribution function (e.g. a Gaussian curve). However, due to weather conditions, flocking behaviour, etc., the day-to-day variation is typically larger than expected by a Poisson process. Such an overdispersed Poisson process can be modelled (e.g. using a quasi-Poisson or negative binomial error distribution). If weather effects are well known, they can be included as covariates. Unknown, such variation can be modelled in the error structure by assuming correlated migration activity between species (which frequently is found and can be due to, e.g., weather affecting trapping numbers of different species similarly, as well as overlapping seasonal distributions) or allowing for autocorrelated residuals. Assuming that correlated migration activity is reflected in correlated summary statistics for the phenological distribution, the former approach will also account for the inflated Type I error rate expected when comparing phenological distributions of different species.

Bayesian methods enable restricting phenological distributions to realistic values by informative priors. A nice feature with the Bayesian approach is the opportunity to quite easily build hierarchical models accounting simultaneously for uncertainty in both the distribution of migration passage time, as well as the further analysis, such as advancement of timing over years.

\subsubsection{Interpretation}

Model-based estimators of phenology can be more robust against unknown weather effects on capture success, and it is straightforward to account for vary- 
ing observation effort and truncated sampling periods. However, if there is large day-to-day variation in the number of actually migrating birds, the true quantiles of the arrival distribution in a given year may be poorly estimated. Hence, fitting a seasonal distribution curve is a sensible approach to modelling the underlying ('latent') distribution of arrivals, and its robustness makes it well suited for describing and detecting long-term changes in the distribution, but poorly suited for picking up deviations from the postulated model.

\section{MODELLING CHANGES IN PHENOLOGY}

Recently observed changes in the timing of bird migration have been a major impetus to the renewed interest in bird migration phenology. However, as we have seen, it is not obvious how to parameterize phenology. Traditionally, some simply observed (e.g. first arrival date) or aggregate (mean or median) measure has been used. This may be justified from lack of knowledge on how populations and population segments segregate in time, but, on the other hand, recent studies indicate that different phases (such as early, middle, late) of migration frequently respond differently. Hence, it is recommended that all phases of bird migration should be studied when possible (Lehikoinen et al. 2004, Sparks et al. 2005). Some early (e.g. 5th or 10th) and late (e.g. 90th or 95th) percentiles have increasingly been reported in addition to the median (Vähätalo et al. 2004, Jonzén et al. 2006, Tøttrup et al. 2006a). This is also the case for studies on the timing of migration in fish (Antonsson \& Gudjonsson 2002, Dahl et al. 2004). Obviously, the modelling of changes in phenology over time relies on a sensible model of phenology, a sensible parameterization and sensible parameter estimates. In Sections 3.2 and 3.3 we discussed tools for exploring these issues (smoothing) and providing robust parameterization and estimates of phenology (fitting seasonal distribution curves). We will, in the following, discuss some methods for modelling change in quantiles, regardless of whether these were obtained directly from the raw data, from smooths or from a modelled distribution.

\subsection{Correlations}

Calculating linear correlation coefficients is a quick and easy way to look or test for relationships between variables. Nearly all of the reviewed studies report some sort of correlation, and several studies use Pearson's correlation coefficients as a major tool (e.g.
Hubálek 2003, 2004). It is a common belief that correlation coefficients are more robust than regression coefficients to violation of parametric assumptions. This is not the case for Pearson's correlation coefficient, which builds on assumptions similar to ordinary least-squares linear regression. There are nonparametric alternatives, however - the 2 most widely known being Spearman's rho and Kendall's tau, both based on rank transformations of the variables. The former was used by Sokolov et al. (1998), Vähätalo et al. (2004) and Rainio et al. (2006). Spearman's rho can be regarded as a special case of Pearson's correlation, whereby the data are replaced by their ranks. Hence, the assumption of a linear relationship between the variables is replaced by the weaker assumption of a monotonic relationship, and the data need not be on an interval scale (an ordinal scale suffices). This means that we, for instance, need not assume that the response of migration timing to the NAO index is the same near the low (negative) end as it is near the high (positive) end.

The partial correlation coefficient between 2 variables $X$ and $Y$ removes the effect of 1 or a set of confounding variables $\boldsymbol{Z}$. In analogy with the simple (Pearson's) correlation coefficient, the square of the partial correlation coefficient equals the partial $\mathrm{R}^{2}$. If either $X$ or $Y$ is a predictor variable for the other, it may be of interest to partial out the effect of some covariate, such as observation effort (Vähätalo et al. 2004, Rainio et al. 2006) before letting the variable enter the analysis. Doing this by using partial correlation is, in practice, the same as doing a linear regression in which variables are detrended by using the residuals from a linear regression. If $X$ and $Y$ are both predictor variables, detrending should eliminate the need for an interaction term. Hence, Jonzén et al. (2006) detrended the NAO winter index prior to regressing arrival percentiles on the variables 'Year' and 'NAO winter index', since a (weak) linear relationship was found between the 2 predictors.

In correlative studies on time series, autocorrelation in 1 or both investigated variables may give rise to spurious correlations (i.e. overly strong relationships and false rejection of the null hypothesis; see e.g. Pyper \& Peterman 1998). The problem is present in simple correlation tests, as well as in linear multiple regression and related techniques, and is, unfortunately, often neglected. Some ways to handle the problem include adjusting the degrees of freedom (Post \& Stenseth 1998, Pyper \& Peterman 1998), assessing significance levels using randomization tests or Monte Carlo simulation (Piha et al. 2007) and removing autocorrelation (due to, e.g., linear and seasonal trends) prior to analysis (prewhitening; $\mathrm{cf}$. Chatfield 1996). 

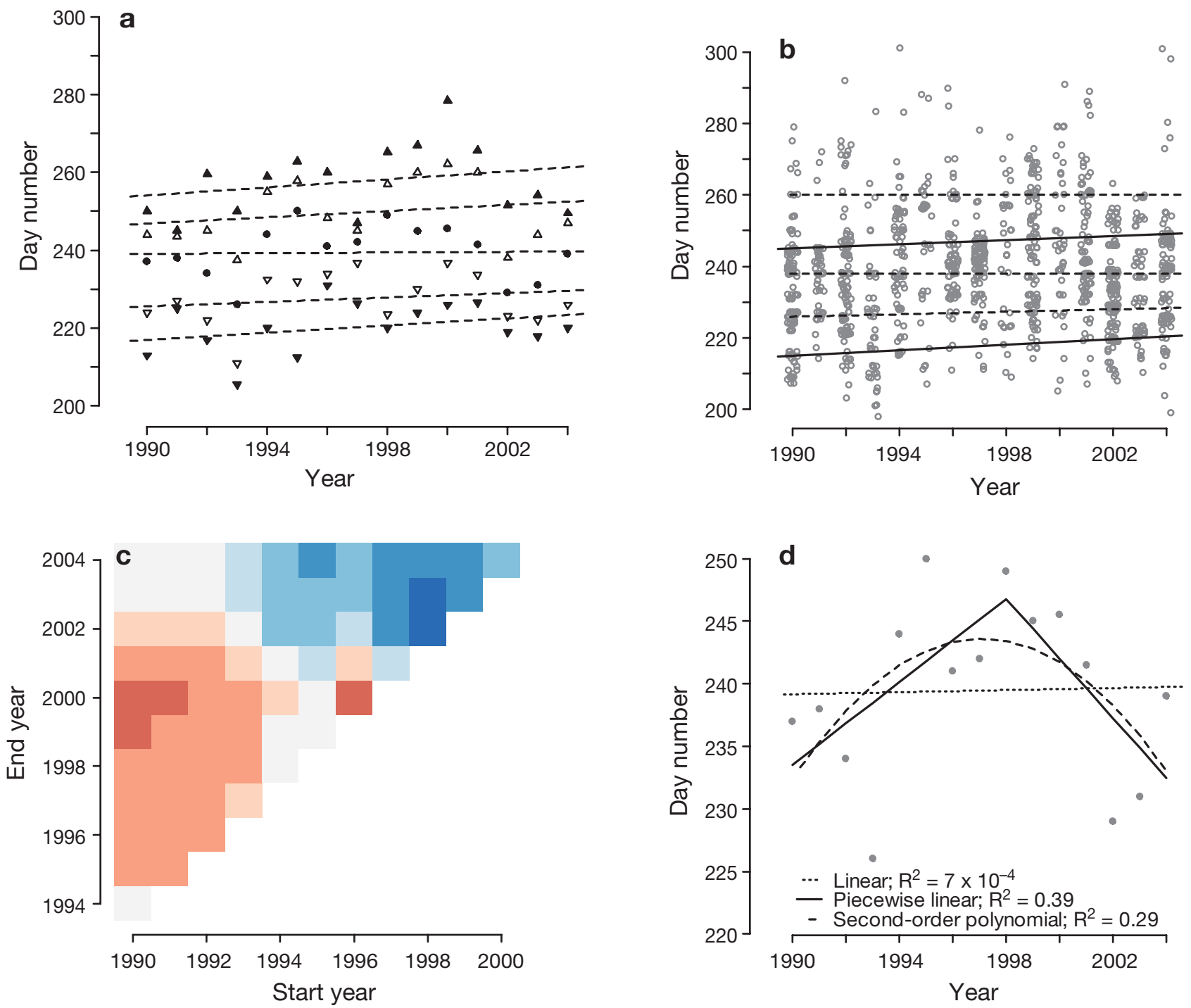

Fig. 4. Sylvia borin. Various methodological approaches to the analysis of trends in the timing of bird migration, illustrated using data previously presented. (a) Regression on sample quantiles (10th $(\boldsymbol{\nabla}), 25$ th $(\nabla), 50$ th $(\boldsymbol{\bullet}), 75$ th $(\Delta)$, and 90th $(\boldsymbol{\Delta})$ percentiles); (b) quantile regression (same quantiles as in previous plot, observations of individual birds are jittered to enhance visibility); for both (a) and (b), significant trends are indicated with solid lines, non-significant trends with dashed lines. (c) Mann-Kendall statistic as a non-parametric indicator of strength and directionality of trends (the colour scale ranges from -1 [dark blue] to 1 [dark red], where positive values indicate positive trends); and (d) fitting a linear, curvilinear and piecewise linear trend to median observation dates

\subsection{Linear models}

Phrasing the research question within the framework of linear models or GLMs allows some flexibility with respect to the model and error structure. The variant most frequently reported is, however, simple linear regression of migration timing on year (Cotton 2003, Hüppop \& Hüppop 2003, Marra et al. 2005). Comparing the timing of migration in different periods is an alternative that is also useful for metaanalysis or sparse data (Zalakevicius 2001, Tryjanowski et al. 2002, Butler 2003), but the delimitation of periods is essentially subjective. As in the case of modelling phenology itself, it is frequently not obvious which covariates should be important or at which temporal and spatial scales they should be considered, and important covariates may be unobservable (e.g. food availability). Hence, it has been common to use a proxy variable, such as the (usually winter) NAO index (Hurrell 1995, Hurrell et al. 2003, Hüppop \& Hüppop 2003, Stenseth et al. 2003), temperatures upon arrival or en route (Ahola et al. 2004), or rainfall/vegetation greenness in winter quarters (Saino et al. 2004). 
In many cases, we will only have a single measurement of the response variable for each value of the predictor variable, as in the case of analyzing trends in migration date for garden warblers at Lista (Fig. 4a). However, we sometimes have data from several bird observatories available or wish to analyze data on several species. In cases where we have some grouping of the data according to some classification variable(s) (e.g. repeated-measures data, longitudinal data, multilevel data, block designs), mixed-effects models allow more powerful modelling by a flexible specification of the covariance structure of the model (Pinheiro \& Bates 2000). Jenni \& Kéry (2003), Jonzén et al. (2006) and Rainio et al. (2006) applied such models to bird migration data. They distinguish between fixed effects (associated with study design and assumed to be measured without error, such as migratory status classified as long-distance, short-distance, or partial migrants) and random effects describing the variability between subjects at each particular level. Effects may be nested within each other. This allows, for instance, for a hierarchical decomposition of variance into variance among genera and variance among species of a genus, the modelling of random and independent year-toyear variability between species and the modelling of interactions between a random and a fixed effect (e.g. a random slopes model where NAO is allowed to have different effects according to bird observatory). Structure in the error term may also be specified, enabling the modelling of autocorrelation structures and correlated random fluctuations across bird observatories.

While time series usually are short and researchers do not wish to discard data, we should not impose a linear fit over time windows for with the data suggest something else. An alternative to choosing time windows a priori would be to fit piecewise linear functions. This appears to be an overlooked issue in the analysis of phenological time series, though Dose \& Menzel (2004) approached the issue from a Bayesian perspective and found that the likelihood of models with a breakpoint (a change in slope) was far higher than models without. There are several approaches to fitting (including b-splines, joint optimization with breakpoints included, and modelling a smooth transition between slopes), though it is problematic if the number of breakpoints needs to be estimated as well. For the present example, we only have 15 yr of data, so inspecting the scatterplot clearly reveals the problem with assuming a linear model for the whole period (Fig. 4d). However, for longer time series it may be helpful to search for plausible ranges for trends and breakpoints using non-parametric test statistics (assuming a monotonous relationship, but not assuming linearity) that indicate the strength and significance of trends. Of course, these may also be used as a non-parametric alternative for assessing trends; see the supplementary online appendix. One alternative is the Mann-Kendall statistic (Mann 1945; see Novotny \& Stefan 2007 for an application), which can be written $S=\sum_{i=1}^{n-1} \sum_{j=i+1}^{n} \operatorname{Sgn}\left(X_{j}-X_{i}\right)$, where

$$
\operatorname{Sgn}(\theta)=\left\{\begin{array}{r}
+1, \theta>0 \\
0, \theta=0 \\
-1, \theta<0
\end{array}\right.
$$

and is asymptotically normally distributed. A scaled version is plotted for various combinations of start and end years in Fig. 4c (here leaving out the significance level for the purpose of visual simplicity).

\subsection{Quantile regression}

Quantile regression (Fig. 4b) is an elegant alternative to ordinary linear regression on sample quantiles. Tøttrup et al. (2006a) fitted trends in the timing of bird migration at Christiansø using both methods. They found that slopes calculated using the 2 methods were overall correlated and quite similar, but quantile regression usually produced stronger and more significant slopes. Cade \& Noon (2003) provide a nice and gentle introduction to the method. In essence, separate regression lines are fitted for each of the specified quantiles of the distribution of the response variable. This is done by minimizing a sum of weighted absolute errors rather than the sum of squared errors. By allowing responses to differ in different parts of the response distribution, the method relaxes distributional assumptions. In particular, ordinary regression techniques assume that variance is homogenous across years, which most frequently is not the case. For a more detailed discussion of the method, we refer to the supplementary online appendix (available at www.int-res.com/articles/ suppl/c035p059_app.pdf).

\subsection{Time series methods}

A time series is a collection of observations made sequentially in time (Chatfield 1996). Data on daily trapping numbers of birds or annual estimates of arrival time are examples of time series in which the data points may be temporally dependent. Whereas the use of time-series analysis has become common practice among ecologists working on population dynamics (e.g. Bjørnstad \& Grenfell 2001), we know of only 1 example of explicit time-series modelling of bird phenology data. Forchhammer et al. (2002) analyzed data on the spring arrival time of birds within an autoregressive modelling framework. An autoregressive model (Box et al. 1994) of order $p$ can be written: $X_{t}=a_{1} X_{t-1}+a_{2} X_{t-2}$ 
$+\ldots+a_{p} X_{t-\mathrm{p}}+\varepsilon_{t}$, where $X_{t}$ is an observation at time $t$ (e.g. first arrival date in year $t$ ), $\varepsilon_{t}$ is a purely random process with zero mean and variance $\sigma^{2}$, and $a_{p}$ is the autoregression coefficient with lag $p$.

Forchhammer et al. (2002) built upon a conceptual model developed by Post et al. (2001). First arrival date in year $t$ was modelled as a function of the arrival time in the 2 preceding years, and NAO was included as a covariate with and without a time lag. 'Year' was included as a covariate to capture linear trends in arrival. The autoregression coefficients measure the structural dynamics, and the idea was to contrast the influence of NAO and the temporal dependence with respect to spring time arrival. Even though the approach is both elegant and generally appealing, the ecological interpretation of the results is far from trivial and the estimates of autoregression coefficients are sensitive to observation error (e.g. Freckleton et al. 2006).

\section{DISCUSSION}

The wide-ranging biological consequences of global climate change have been increasingly recognized (Stenseth et al. 2002, Walther et al. 2002, IPCC 2007). Challenges in the future study of climate change impacts on avian biology have recently been reviewed by Møller et al. (2004). In this paper, we have presented an overview of different approaches and techniques that have been or may become helpful in the analysis of the signal of bird migration as picked up by observation and trapping efforts. The phenomenological description we obtain from observing migration at a fixed point is complex and noisy. Only a small part of the total flux of bird migration is recorded at ground level, and it is poorly known to what extent this matches the pattern aloft. One study relating mist-netting numbers to nocturnal migration recorded by a passive infrared device does, however, suggest that the 2 are positively correlated (Zehnder \& Karlsson 2001). For most species, ground level monitoring data are our only source of information on the detailed dynamics of bird migration, due to the limitations of radar studies and wildlife telemetry (Gauthreaux \& Belser 2003, Cochran \& Wikelski 2005). While anticipating technological aid (Wikelski et al. 2007), it may pay off well to make use of the large and increasing amount of long-term data from bird observatories, recording bird migration phenology in great detail. A recent review of trends in the timing of spring migration reveals large differences across species and geography, but suggests consistent patterns within a species (Rubolini et al. 2007, this issue). This is not surprising, since other indicators of seasonality, such as vegetation greenness and local temperatures, are not changing uniformly across space either (see Stöckli \& Vidale 2003), and species may be sensitive to different cues over different time windows (Both \& te Marvelde 2007, this issue). Hence, moving further from regarding these data simply as noisy measures of timing is likely to be highly rewarding.

\subsection{Phenomenological description}

Whereas a selection of sample statistics has been the most common way of describing bird migration phenology, we have presented 2 alternative approaches: smoothing and fitting of a phenological distribution function. The choice between them should depend on the quality of the data and the questions posed, but is also likely to be affected by any preference for exploratory or confirmatory approaches to data analysis. Smoothing takes the data at hand and yields a description of it at a controllable detail level, but does not account for observation error and truncated data, and only to a limited and variable extent for missing data. If the data are poor and/or sparse, fitting a seasonal distribution curve should be a more robust alternative, particularly for extracting information on the 'underlying' timing of migration. This would also typically be the preferred choice if following a confirmatory approach to data analysis. On the other hand, if the data are of high quality, smoothing suggests likely shapes of the seasonal distribution curve that may be fed into confirmatory analysis using, for instance, a generalized additive model (GAM). Some smoothing techniques, in particular wavelet analysis, are useful for describing time series at different observation scales, which is important by its own virtue, but also useful for stimulating thinking about the nature of the data and suggesting covariates, as well as the range of observation scales over which they may be important. Considerations regarding the scales of observation and ecological processes (see e.g. Peterson \& Parker 1998) have now become commonplace in disciplines such as landscape ecology, but were characterized as a paradigm shift when they entered the scene.

\subsection{Individual- and population-level mechanisms}

Mechanistic explanations ultimately require detailed knowledge at the levels of populations and individuals. By analyzing genetic markers and the isotopic and trace element composition of feathers, we are able to gain some coarse insight into the migratory connectivity of individuals (i.e. the linkage between wintering and summering areas), as well as their intermediate stopover sites (Webster et al. 2002). Such insight is valuable in understanding trends in the timing of life- 
history events. For instance, Marra et al. (1998) showed that the quality of the wintering habitat of individual American redstarts Setophaga ruticilla affected their timing of and physical condition upon spring departure. This is likely to be reflected in their arrival at breeding grounds, and indeed Norris et al. (2004) found significant relationships between the quality of winter habitat and arrival, with a poorer quality habitat resulting in later arrival.

Carry-over effects between seasons may also be mediated by mortality, which can be substantially higher during migration than during other times of the year (Sillett \& Holmes 2002, Newton 2006). Migration, arrival, or breeding can, of course, only be recorded for individuals that survive migration, and the observed distribution of timing is only representative for the survivors. Hence, if individuals that are characteristic for one part of the distribution (e.g. related to sex, age, or wintering area) survive less well than others in some years, then this will be reflected in the distribution even if the individual phenological traits are the same.

Mortality during the period of migration will affect the distribution of arrivals even if mortality is indiscriminate, since individuals arriving late will have to survive for a longer period of time and, hence, have a lower probability of surviving until arrival. This complication should be considered when analyzing the time of arrival as an individual trait (e.g. in order to study selection or effects on individual performance), but is not necessarily a concern when estimating arrival time of the survivors that make up the population of potential breeders. In the jargon of statistical time-failure ('survival') analysis, individuals that die or are removed before 'failure' (i.e. the event of interest) are 'right censored' (Venables \& Ripley 2002). Gienapp et al. (2005) used a proportional hazard time-failure model to describe the within-year relationship between changes in daily temperature and time of egg laying. However, neither proportional hazard models, nor accelerated life models (Venables \& Ripley 2002) are appropriate for modelling between-year variation in migration phenology, since these models would imply larger variation in arrival date when mean arrival date is late, which is not realistic. Parametric hazard functions can, however, be fitted to individual data by maximum-likelihood methods (Venables \& Ripley 2002), even in cases where the exact time of the event or death is not known (Ergon et al. 2008).

\subsection{Recommendations}

Our focus throughout this paper has been rather specifically on bird migration data from standardized monitoring programmes, but the problems, methods and approaches presented are general and applicable also to less standardized and more sparse data, as well as to other phenological study systems. If the data are of high quality, both smoothing and fitting a phenological distribution function will be robust alternatives for extracting summary statistics, and smoothing reveals details in the within-season distribution of timing. Smooths may be included in confirmatory models, using for instance GAMs, but for sparse, truncated, and/or uncertain data, we recommend fitting a parametric distribution curve. Better fits can be obtained if we allow some flexibility in the distribution curve and error structure. This is also the case when modelling trends over time. Mixed-effects models are a flexible and powerful alternative to analyzing trends separately for each species and grouping factor, and, though linear trends may seem to be a natural choice, they need not always be imposed over time windows selected a priori.

While the fields of research on bird migration and phenology are old and mature, the field of climate change impacts on bird migration is young and in a phase of phenomenological exploration and dissection. There are great challenges in merging phenomenological and mechanistic approaches, but we think there will also be great rewards, not least in terms of better separation between 'true' phenology and patterns imposed by the observation process.

Acknowledgements. This work was financially supported and hosted by the EcoClim Nordic Centre of Excellence, jointly funded by the Nordic Council of Ministers and the natural science funding agencies of the Nordic countries. E.K. was supported by a PhD grant from the University of Oslo. N.J. and J.K. were financially supported by the Swedish Research Council. We thank generations of dedicated bird ringers and observers for their sustained efforts. The comments of 3 anonymous reviewers helped us to sharpen the presentation.

\section{LITERATURE CITED}

Ader A (1993) Application of the method of iterative moving average for detecting birds' migration waves. Proc Est Acad Sci Ecol 3:17-26

Ahola M, Laaksonen T, Sippola K, Eeva T, Rainio K, Lehikoinen E (2004) Variation in climate warming along the migration route uncouples arrival and breeding dates. Glob Change Biol 10:1610-1617

Anselin L (1995) Local indicators of spatial association-LISA. Geogr Anal 27:93-115

Antonsson T, Gudjonsson S (2002) Variability in timing and characteristics of Atlantic salmon smolt in Icelandic rivers. Trans Am Fish Soc 131:643-655

Azzalini A (1985) A class of distributions which includes the normal ones. Scand J Stat 12:171-178

Azzalini A (2006) R package 'sn': the skew-normal and skew-t distributions (Version 0.4-2). Available at http:// azzalini.stat.unipd.it/SN, accessed on 15 October 2007

Barriocanal C, Robson D (2007) Spring passage of willow 
warbler Phylloscopus trochilus across the western Mediterranean: comparing islands with the mainland. Ardea 95:91-96

Bibby CJ (2000) Bird census techniques. Academic Press, London

Bjørnstad ON, Grenfell BT (2001) Noisy clockwork: time series analysis of population fluctuations in animals. Science 293:638-643

Both C, te Marvelde L (2007) Climate change and timing of avian breeding and migration throughout Europe. Clim Res 35:93-105

Box GEP, Jenkins GM, Reinsel GC (1994) Time series analysis: forecasting and control. Prentice-Hall, Englewood Cliffs, NJ

Browne SJ, Aebischer NJ (2003) Temporal changes in the migration phenology of turtle doves Streptopelia turtur in Britain, based on sightings from coastal bird observatories. J Avian Biol 34:65-71

Busse P (1996) Modelling of the seasonal dynamics of bird migration. Ring 18:97-119

Butler CJ (2003) The disproportionate effect of global warming on the arrival dates of short-distance migratory birds in North America. Ibis 145:484-495

Cade BS, Noon BR (2003) A gentle introduction to quantile regression for ecologists. Front Ecol Env 1:412-420

Chatfield C (1996) The analysis of time series: an introduction. Chapman \& Hall, London

Cochran WW, Wikelski M (2005) Individual migratory tactics of New World Catharus thrushes: current knowledge and future tracking options from space. In: Marra P, Greenberg R (eds) Birds of two worlds. Johns Hopkins University Press, Baltimore, MD, p 274-289

Cooke WW (1913) The relation of bird migration to the weather. Auk 30:205-231

Coppack T, Tøttrup AP, Spottiswoode C (2006) Degree of protandry reflects level of extrapair paternity in migratory songbirds. J Ornithol 147:260-265

Cotton PA (2003) Avian migration phenology and global climate change. Proc Natl Acad Sci USA 100:12219-12222

Dahl J, Dannewitz J, Karlsson L, Petersson E, Löf A, Ragnarsson B (2004) The timing of spawning migration: implications of environmental variation, life history, and sex. Can J Zool 82:1864-1870

de Valpine P, Hastings A (2002) Fitting population models incorporating process noise and observation error. Ecol Monogr 72:57-76

Dempster AP, Laird NM, Rubin DB (1977) Maximum likelihood from incomplete data via the EM algorithm. J R Stat Soc B Met 39:1-38

Dose V, Menzel A (2004) Bayesian analysis of climate change impacts in phenology. Glob Change Biol 10:259-272

Ergon T, Yoccoz NG, Nichols JD (2008) Estimating latent time of maturation and survival costs of reproduction in continuous time from capture-recapture data. Environ Ecol Stat (in press)

Forchhammer MC, Post E, Stenseth NC (2002) North Atlantic Oscillation timing of long- and short-distance migration. J Anim Ecol 71:1002-1014

Francis CM, Hussel DJT (1998) Changes in numbers of land birds counted in migration at Long Point bird observatory, 1961-1977. Bird Popul 4:37-66

Freckleton RP, Watkinson AR, Green RE, Sutherland WJ (2006) Census error and the detection of density dependence. J Anim Ecol 75:837-851

Gauthreaux SA, Belser CG (2003) Radar ornithology and biological conservation. Auk 120:266-277

Gienapp P, Hemerik L, Visser ME (2005) A new statistical tool to predict phenology under climate change scenarios. Glob Change Biol 11:600-606

Gordo O (2007) Why are bird migration dates shifting? A review of weather and climate effects on avian migratory phenology. Clim Res 35:37-58

Hastie TJ, Tibshirani RJ (1990) Generalized additive models. In: Cox DR, Hinkley DV, Rubin D, Silverman BW (eds) Monographs on statistics and applied probability, 43. Chapman \& Hall/CRC, London

Hedenström A, Alerstam T (1997) Optimum fuel loads in migratory birds: distinguishing between time and energy minimization. J Theor Biol 189:227-234

Helm B, Piersma T, van der Jeugd H (2006) Sociable schedules: interplay between avian seasonal and social behaviour. Anim Behav 72:245-262

Hötker H (2002) Arrival of pied avocets Recurvirostra avosetta at the breeding site: effects of winter quarters and consequences for reproductive success. Ardea 90:379-387

Hubálek Z (2003) Spring migration of birds in relation to North Atlantic Oscillation. Folia Zool (Brno) 52:287-298

Hubálek Z (2004) Global weather variability affects avian phenology: a long-term analysis, 1881-2001. Folia Zool (Brno) 53:227-236

Hüppop O, Hüppop K (2003) North Atlantic Oscillation and timing of spring migration in birds. Proc R Soc Lond B 270:233-240

Hüppop O, Winkel W (2006) Climate change and timing of spring migration in the long-distance migrant Ficedula hypoleuca in central Europe: the role of spatially different temperature changes along migration routes. J Ornithol 147:344-353

Hurrell JW (1995) Decadal trends in the North Atlantic Oscillation: regional temperatures and precipitation. Science 269:676-679

Hurrell JW, Kushnir Y, Ottersen G, Visbeck M (2003) An overview of the North Atlantic Oscillation. In: Hurrell JW, Kushnir Y, Ottersen G, Visbeck M (eds) The North Atlantic Oscillation: climate significance and environmental impact. Geophysical Monograph Series 134. American Geophysical Union, Washington, DC, p 1-35

IPCC (Intergovernmental Panel on Climate Change) (2007) Impacts, adaptation and vulnerability. Contribution of Working Group II to the 4th assessment report of the IPCC, Cambridge University Press, Cambridge

Iwasa Y, Levin SA (1995) The timing of life-history events. J Theor Biol 172:33-42

James D, Hornik K (2007) Chron: chronological objects which can handle dates and times. R package, Version 2.3-10, R Foundation for Statistical Computing, Vienna

Jenni L, Kéry M (2003) Timing of autumn bird migration under climate change: advances in long-distance migrants, delays in short-distance migrants. Proc R Soc Lond B 270:1467-1471

Jonzén N, Lindén A, Ergon T, Knudsen E and others (2006) Rapid advance of spring arrival dates in long-distance migratory birds. Science 312:1959-1961

Jonzén N, Hedenström A, Lundberg P (2007) Climate change and the optimal arrival of migratory birds. Proc R Soc Lond B 274:269-274

Jounela P, Suuronen RBM, Koljonen ML (2006) Interactions between grey seal (Halichoerus grypus), Atlantic salmon (Salmo salar), and harvest controls on the salmon fishery in the Gulf of Bothnia. ICES J Mar Sci 63:936-945

Kania W (1981) The autumn migration of the chaffinch Fringilla coelebs over the Baltic coast in Poland. Acta Ornithol 18:375-418 
Knape J, Jonzén N, Sköld M, Sokolov L (in press) Multivariate state space modelling of bird migration count data. Environ Ecol Stat (in press)

Koenker R (2006) quantreg: quantile regression. R package Version 4.05, R Foundation for Statistical Computing, Vienna

Kopiec K (1997) Seasonal pattern of the blackcap (Sylvia atricapilla) autumn migration at the Polish Baltic coast. Ring 19:41-58

Kopiec-Mokwa K (1999) Dates of migration waves-A coincidence or an effect of biologically based mechanism? Improvement of the method of analysing the seasonal migration dynamics. Ring 21:131-144

Lack D (1960) The influence of weather on passerine migration. A review. Auk 77:171-209

Lack D (1968) Ecological adaptations for breeding in birds. Methuen, London

Lehikoinen E (1993) Old bird station data useless? No wayor not all of it, anyway. Vår Fuglefauna Suppl 1:53-57

Lehikoinen E, Sparks TH, Zalakevicius M (2004) Arrival and departure dates. In: Møller AP, Fiedler W, Berthold P (eds) Birds and climate change. Adv Ecol Res 35:1-31

Liechti F (2006) Birds: Blowin' by the wind? J Ornithol 147: 202-211

MacMynowski DP, Root TL (2007) Climate and the complexity of migratory phenology: sexes, migratory distance, and arrival distributions. Int J Biometeorol 51:361-373

Maechler M (2007) Sfsmisc: utilities from Seminar fuer Statistik ETH Zurich. R package Version 0.95-9, Seminar fuer Statistik ETH, Zurich

Malo JE (2002) Modelling unimodal flowering phenology with exponential sine equations. Funct Ecol 16:413-418

Mann HB (1945) Nonparametric tests against trend. Econometrica 13:245-259

Mäntyniemi S, Romakkaniemi A (2002) Bayesian mark-recapture estimation with an application to a salmonid smolt population. Can J Fish Aquat Sci 59: $1748-1758$

Marra PP, Hobson KA, Holmes RT (1998) Linking winter and summer events in a migratory bird by using stable-carbon isotopes. Science 282:1884-1886

Marra PP, Francis CM, Mulvihill RS, Moore FR (2005) The influence of climate on the timing and rate of spring bird migration. Oecologia 142:307-315

McLeod AI (2005) Kendall: Kendall rank correlation and Mann-Kendall trend test. R package Version 2.0, R Foundation for Statistical Computing, Vienna

Michalonek D, Busse W, Busse P (2004) Seasonal migration pattern of owls at Bukowo-Kopan station (N Poland) in 2000-2003. Ring 26:13-21

Miller MW, Greenstone EM, Greenstone W, Bildstein KL (2002) Timing and magnitude of broad-winged hawk migration at Montclair Hawk Lookout, New Jersey, and Hawk Mountain Sanctuary, Pennsylvania. Wilson Bull 114: 479-484

Mills AM (2005) Changes in the timing of spring and autumn migration in North American migrant passerines during a period of global warming. Ibis 147:259-269

Møller AP (2001) Heritability of arrival date in a migratory bird. Proc R Soc Lond B Biol Sci 268:203-206

Møller AP, Berthold P, Fiedler W (2004) The challenge of future research on climate change and avian biology. In: Møller AP, Fiedler W, Berthold P (eds) Birds and climate change. Adv Ecol Res 35:237-245

Moore FR, Yong W (1991) Evidence of food-based competition among passerine migrants during stopover. Behav Ecol Sociobiol 28:85-90
Morbey YE, Ydenberg RC (2001) Protandrous arrival timing to breeding areas: a review. Ecol Lett 4:663-673

Morgan BJT (2000) Applied stochastic modelling. Arnold texts in statistics. Arnold Publishers, London

Newton I (2006) Can conditions experienced during migration limit the population levels of birds? J Ornithol 147: 146-166

Norris DR, Marra PP, Kyser TK, Sherry TW, Ratcliffe LM (2004) Tropical winter habitat limits reproductive success on the temperate breeding grounds in a migratory bird. Proc R Soc Lond B 271:59-64

Novotny EV, Stefan HG (2007) Stream flow in Minnesota: indicator of climate change. J Hydrol 334:319-333

Nowakowski JK (2002) Do numbers of great tits Parus major caught at ringing stations reflect the real intensity of passage? Ornis Svec 12:197-201

Nowakowski JK, Remisiewicz M, Keller M, Busse P, Rowinski P (2005) Synchronisation of the autumn mass migration of passerines: a case of robins Erithacus rubecula. Acta Ornithologica Warzaw 40:103-115

Percival DB, Walden AT (2000) Wavelet methods for time series analysis. In: Gill R, Ripley BD, Ross S, Stein M, Williams D (eds) Cambridge series in statistical and probabilistic mathematics. Cambridge University Press

Peron G, Henry PY, Provost P, Dehorter O, Julliard R (2007) Climate changes and post-nuptial migration strategy by two reedbed passerines. Clim Res 35:147-157

Peterson DL, Parker VT (eds) (1998) Ecological scale: theory and applications. In: Complexity in ecological systems series. Columbia University Press, New York

Piha M, Lindén A, Pakkala T, Tiainen J (2007) Linking weather and habitat to population dynamics of a migratory farmland songbird. Ann Zool Fenn 44:20-34

Pinheiro JC, Bates DM (2000) Mixed-effects models in S and S-PLUS. In: Chambers J, Eddy W, Härdle W, Sheather S, Tierney L (eds) Statistics and computing series. Springer, New York

Post E, Stenseth NC (1998) Large-scale climatic fluctuation and population dynamics of moose and white-tailed deer. J Anim Ecol 67:537-543

Post E, Forchhammer MC, Stenseth NC, Callaghan TV (2001) The timing of life-history events in a changing climate. Proc R Soc Lond B 268:15-23

Pulido F, Berthold P, Mohr G, Querner U (2001) Heritability of the timing of autumn migration in a natural bird population. Proc R Soc Lond B 268:953-959

Pyper BJ, Peterman RM (1998) Comparison of methods to account for autocorrelation in correlation analyses of fish data. Can J Fish Aquat Sci 55:2127-2140

Quinn TP, Unwin MJ, Kinnison MT (2000) Evolution of temporal isolation in the wild: genetic divergence in timing of migration and breeding by introduced chinook salmon populations. Evolution 54:1372-1385

R Development Core Team (2006) R: a language and environment for statistical computing. R Foundation for Statistical Computing, Vienna, Austria. Available at www.r-project. org, accessed on 15 October 2007

Rainio K, Laaksonen T, Ahola M, Vähätalo AV, Lehikoinen E (2006) Climatic responses in spring migration of boreal and arctic birds in relation to wintering area and taxonomy. J Avian Biol 37:507-515

Rainio K, Tøttrup AP, Lehikoinen E, Coppack T (2007) Effects of climate change on the degree of protandry in migratory songbirds. Clim Res 35:107-114

Remisiewicz M, Baumanis J (1996) Autumn migration of goldcrest (Regulus regulus) at the eastern and southern Baltic coast. Ring 18:3-36 
Roff DA (1997) Evolutionary quantitative genetics. Chapman \& Hall, New York

Rubolini D, Møller AP, Rainio K, Lehikoinen E (2007) Intraspecific consistency and geographic variability in temporal trends of spring migration phenology among European bird species. Clim Res 35:135-146

Saino N, Szép T, Romano M, Rubolini D, Spina F, Møller AP (2004) Ecological conditions during winter predict arrival date at the breeding quarters in a trans-Saharan migratory bird. Ecol Lett 7:21-25

Saino N, Rubolini D, Jonzén N, Ergon T, Montemaggiori A, Stenseth NC, Spina F (2007) Temperature and rainfall anomalies in Africa predict timing of spring migration in trans-Saharan migratory birds. Clim Res 35:123-134

Schafer JL (1999) Multiple imputation: a primer. Stat Methods Med Res 8:3-15

Schaub M, Jenni L (2000) Fuel deposition of three passerine bird species along the migration route. Oecologia 122: 306-317

Schaub M, Liechti F, Jenni L (2004) Departure of migrating European robins, Erithacus rubecula, from a stopover site in relation to wind and rain. Anim Behav 67:229-237

Sillett TS, Holmes RT (2002) Variation in survivorship of a migratory songbird throughout its annual cycle. J Anim Ecol 71:296-308

Silverman BW (1986) Density estimation for statistics and data analysis. In: Cox DR, Hinkley DV, Keiding N, Reid N, Rubin DB, Silverman BW (eds) Monographs on statistics and applied probability, 26. Chapman \& Hall/CRC, London

Singh RP, Oza SR, Pandya MR (2006) Observing long-term changes in rice phenology using NOAA-AVHRR and DMSP-SSM/I satellite sensor measurements in Punjab, India. Curr Sci 91:1217-1221

Sokolov LV, Kosarev VV (2003) Relationship between timing of arrival of passerines to the Courish Spit and North Atlantic Oscillation index (NAOI) and precipitation in Africa. Tr Zool Inst 299:141-154

Sokolov LV, Markovets MY, Shapoval AP, Morozov YG (1998) Long-term trends in the timing of spring migration of passerines on the Courish Spit of the Baltic Sea. Avian Ecology and Behaviour 1:1-21

Sparks TH, Bairlein F, Bojarinova JG, Hüppop O and others (2005) Examining the total arrival distribution of migratory birds. Glob Change Biol 11:22-30

Spina F, Massi A, Montemaggiori A (1994) Back from Africa: Who's running ahead? Differential migration of sex and age classes in Palearctic-African spring migrants. Ostrich 65:137-150

Spottiswoode CN, Tøttrup AP, Coppack T (2006) Sexual selection predicts advancement of avian spring migration in response to climate change. Proc R Soc Lond B 273: 3023-3029

Stenseth NC, Mysterud A, Ottersen G, Hurrell JW, Chan KS, Lima M (2002) Ecological effects of climate fluctuations. Science 297:1292-1296

Stenseth NC, Ottersen G, Hurrell JW, Mysterud A and others (2003) Studying climate effects on ecology through the use of climate indices: the North Atlantic Oscillation, El Niño Southern Oscillation and beyond. Proc R Soc Lond B 270: 2087-2096
Stervander M, Lindström Å, Jonzén N, Andersson A (2005) Timing of spring migration in birds: long-term trends, North Atlantic Oscillation and the significance of different migration routes. J Avian Biol 36:210-221

Stöckli R, Vidale PL (2003) European plant phenology and climate as seen in a 20-year AVHRR land-surface parameter dataset. Int J Remote Sens 25:3303-3330

Tøttrup AP, Thorup K, Rahbek C (2006a) Patterns of change in timing of spring migration in North European songbird populations. J Avian Biol 37:84-92

Tøttrup AP, Thorup K, Rahbek C (2006b) Changes in timing of autumn migration in North European songbird populations. Ardea 94:527-536

Trnka A, Prokop P (2006) Do predators cause a change in passerine movement patterns as indicated by mist-net trapping rates? Ardea 94:71-76

Tryjanowski P, Kuzniak S, Sparks TH (2002) Earlier arrival of some farmland migrants in western Poland. Ibis 144:62-68

Vähätalo AV, Rainio K, Lehikoinen A, Lehikoinen E (2004) Spring arrival of birds depends on the North Atlantic Oscillation. J Avian Biol 35:210-216

van Asch M, Visser ME (2007) Phenology of forest caterpillars and their host trees: the importance of synchrony. Annu Rev Entomol 52:37-55

Venables WN, Ripley WN (2002) Modern applied statistics with S. In: Chambers J, Eddy W, Härdle W, Sheather S, Tierney L (eds) Statistics and computing series. Springer, New York

Visser ME, Both C (2005) Shifts in phenology due to global climate change: the need for a yardstick. Proc R Soc Lond B 272:2561-2569

Visser ME, Both C, Lambrechts MM (2004) Global climate change leads to mistimed avian reproduction. In: Møller AP, Fiedler W, Berthold P (eds) Birds and climate change. Adv Ecol Res 35:89-10

Walther GR, Post E, Convey P, Menzel A and others (2002) Ecological responses to recent climate change. Nature 416: 389-395

Weber TP, Houston AI (1997) A general model for timeminimising avian migration. J Theor Biol 185:447-458

Webster MS, Marra PP, Haig SM, Bensch S, Holmes RT (2002) Links between worlds: unraveling migratory connectivity. Trends Ecol Evol 17:76-83

Whitcher B (2006) Waveslim: basic wavelet routines for one-, two- and three-dimensional signal processing. R package version 1.6. Available at www.image.ucar.edu/ whitcher/, accessed on 15 October 2007

Wikelski M, Kays RW, Kasdin NJ, Thorup K, Smith JA, Swenson GW (2007) Going wild: what a global small-animal tracking system could do for experimental biologists. J Exp Biol 210:181-186

Wood SN (2006) Generalized additive models: an introduction with R. In: Carlin BP, Chatfield C, Tanner M, Zidek J (eds) Texts in statistical science. Chapman \& Hall/CRC, Boca Raton, FL

Zalakevicius M (2001) Bird migration and the climate: a review of the studies conducted in Lithuania in the context of climate change. Acta Zoologica Lituanica 11:200-218

Zehnder S, Karlsson L (2001) Do ringing numbers reflect true migratory activity of nocturnal migrants? J Ornithol 142: 173-183 